\title{
CONFIGURACIÓN CONSTITUCIONAL DEL AMPARO EN VENEZUELA
}

JUAN MANUEL GOIG MARTÍNEZ 


\section{SUMARIO}

1. Naturaleza del amparo constitucional.-II. Objetivo y finalidad del amparo en venezuela.- - III. Procedencia del amparo.-1. El amparo contra leyes. - 2. El amparo contra sentencias y resoluciones judiciales. - 3. El amparo frente a actos provenientes del Estado.-4. El amparo por violación del derecho a la libertad: El Habeas Corpus. - 5. Improcedencia de la acción de amparo.-IV. LA LEGITIMACIÓN EN EL PROCESO DE AMPARO.-V. LA COMPETENCIA PARA CONOCER LA ACCIÓN DE AMPARO.-VI. Características del PROCESO DE AMPARO CONSTITUCIONAL. 


\section{CONFIGURACIÓN CONSTITUCIONAL DEL AMPARO EN VENEZUELA}

POR

JUAN MANUEL GOIG MARTÍNEZ

\section{NATURALEZA DEL AMPARO CONSTITUCIONAL VENEZOLANO}

Aunque en el derecho latinoamericano han sido varias las acepticones tradicionales del término amparo que se han manifestado en las Cartas fundamentales ${ }^{1}$, ya sea como sinónimo de recurso o medio de impuganción de resoluciones judiciales, o como concepto para designar los interdictos posesorios, que en la mayor parte de los casos procedian para tutelar la posesión de bienes, pero que, en ocasiones, también se utilizó para la protección de los derechos de carácter personal, ha sido en el sentido relativo a instrumento procesal para la protección de los derechos de la persona humana donde debe considerarse con mayor importancia, pues ha trascendido precisamente a la institución que tutela los derechos consagrados en las Constituciones políticas de los países latinoamericanos ${ }^{2}$.

- Fix Zamudio. "Diversos significados del amparo en el derecho latinoamericano». Boletín informativo de Derecho Comparado. México 1965. Págs. 123 y ss.

2 Niceto Alcalá Zamora. «Enseñanzas y sugerencias de algunos tratadistas latinoamericanos sobre la acción". Estudios de Derecho Procesal. Buenos Aires 1949. 
A tenor de lo establecido en el artículo 49 de la Constitución venezolana, el sentido que se quiere dar al amparo es el establecimiento de una vía jurisdiccional sumaria para restablecer la situación de las personas lesionadas por la violación de los derechos y garantías que la Constitución consagra, y aún de aquellas no consagradas específicamente ${ }^{3}$.

El artículo 1 de la Ley Orgánica de Amparo de la República de Venezuela consagra el amparo como una acción destinada a restablecer el derecho lesionado, pura y simplemente, $y$ a tal objeto lo confirman los artículos 29 y 30 de la misma Ley, al indicar la decisión que lo acuerda.

El amparo venezolano se configura como una acción, un remedio especifico para la tutela de los derechos, mediante el cual se hace valer una pretensión que se deduce contra un sujeto, ya sea público o privado, puesto que no existe una continuidad orgánica entre el acto reclamado y la acción de amparo, sino que con ésta última se pretende evitar que dicho acto lesione o pueda lesionar un derecho.

Aunque el ordenamiento jurídico venezolano articula otros medios, directos unos e indirectos otros, para la tutela de los derechos fundamentales, la Ley de Amparo establece para la interposición del mismo, un procedimiento propio, basado en el antiformalismo y la brevedad, circustancias que no aseguran otros medios establecidos, convirtiendose, de este modo, en una vía autónoma.

El amparo es un instrumento amplio, por cuanto no se limita, en su campo de acción, a la tutela de unos derechos específicos y determinados, sino que amplía su acción a la defensa de todos aquellos derechos y garantías que son inherentes al ser humano (articulo 50 de la Constitución), siendo, a la vez, preventivo y represivo, al no exigir para su interposición que la ivolación o el menoscabo del derecho se haya producido, sino que admite su procedencia ante la amenaza de violación, siempre que ésta sea inminente, posible y realizable.

No es una acción subsidiaria ${ }^{4}$, puesto que, aunque con anterioridad a la promulgación de la Ley de Amparo, la Corte Primera de lo Contencioso-Administrativo, hubiera establecido el criterio de subsidiariedad de la acción ${ }^{5}$, la Ley no exige para su interposición el agotamiento de las

3 Aunque algunos sectores de la doctrina hayan considerado el amparo como un "Derecho de amparo». BreWER CARIAS. "La ley órganica de amparo". Caracas 1988.

- SCPCA 25 de enero de 1984.

5 Criterio contrariado por BREWER CARIAS. "Estado de derecho y control judicial». INAP. Madrid 1987. Pág. 617. 
vías proecedentes, limitándose a afirmar que el amparo no procederá cuando el agraviado haya optado por recurrir las vías judiciales ordinarias, o haya hecho uso de los medios judiciales existentes.

La acción de amparo pretende, ante todo, un efecto restablecedor, tal y como afirma el artículo 29 de la Ley al establecer que la sentencia de amparo deberá señalar lo que ha de cumplirse para lograr el restablecimiento del bien lesionado, $v$ el artículo 30 indica que si se trata de amparo contra omisiones, el efecto de su acogida será la orden de ejecución inmediata e incondicional del acto incumplido.

La Ley Orgánica de Amparo permite lograr la adecuada protección de los derechos a través de una acción de amparo autónoma, que aparece como absolutamente diferente del recurso de inconstitucionalidad de las leyes, de las acciones contencioso-administrativas $y$, por supuesto, del recurso de casación, y con una enorme amplitud protectora, puesto que va dirigida a garantizar todos los derechos constitucionales, que no exige el agotamiento previo de las vías judiciales ${ }^{6}$, tratándose de una acción que procederá cuando no se haya optado por el ejercicio de otras acciones judiciales que permitan, mediante procedimientos breves y sumarios, el restablecimiento de los derechos violados o amenazados de violación, sin que se le pueda aplicar el calificativo de extrordinaria. Ahora bien, sí se trata de un remdio excepcional establecido para otorgar protección a situaciones jurídcas especiales, que no son susceptibles de refutación o contradicción por el Poder Público, por lo que reclaman una solución urgente, si bien el carácter excepcional de la acción de amparo no puede ser entendido en el sentido de conocimiento limitado a un determinado aspecto de la controversia, sino en el de la restricción de su empleo en los casos de excepción en que la índole de los derechos protegidos se requiere una tutela especial.

\section{OBJETO Y FINALIDAD DEL AMPARO EN VENEZUELA}

El Amparo constitucional venezolano es finalístico, como institución persigue una finalidad y describe un uiter teleológico" con una dirección definida que apunta a un solo objetivo, cual es el goce y ejercicio de los derechos y garantías, y en el cauce de la ley, supone la estructura-

- Lo que la hace diferente de la legislación europea, en especial de las legislaciones española y alemana. 
ción del medio jurisdiccional para que la garantía se haga efectiva. El fin del amparo es el restablecimiento de la situación jurídica infringida. El objeto tutelado mediante el ejercicio de la acción de amparo es el goce y ejercicio de los derechos y garantías del hombre.

Se constituye el amparo en Venezuela como un remedio judicial capaz de actualizar derechos y encauzar garantias, tratándose de una tuición inminente, la más generosa y amplia que pudo concebir el constituyente para proteger al hombre y, con ella y en función de ella, sus derechos y el pleno goce correspondiente, para que nadie sea lastimado por el ejercicio del Poder o autoridad, ni por un acto u omisión de particulares.

A través del amparo se resguardan y protegen dos tipos de derechos de carácter general; en primer lugar aquellos que se encuentran consagrados expresamente en la Cosntitución, y en segundo término los derechos constitucionales implícitos ${ }^{7}$ que son aquellos que no figuran expresamente en el texto constitucional ${ }^{8}$.

La propia Ley de Amparo establece en su artículo 1 que el objeto del amparo son los derechos y garantías constitucionales, "lo importante es que afecta concreta y directamente a un precepto constitucional que garantice un derecho de la persona", y por tanto puede hacerse valer frente a aquellos agravios que "en violación de la Cosntitución lesionen al particular en sus derechos»".

También se encuentran protegidos los derechos inherentes de la persona humana con lo cual el campo de protección es muy amplio y extenso, puesto que en él están incluídos los derechos humanos no enumerados en la Constitución, en virtud de su novedad y estado naciente. Dentro de estos derechso se encuentran los llamados «derechos de la solidaridad" ${ }^{10}$, que son consecuencia de las nuevas necesidades del hombre y la colectividad humana en el actual grado de desarrollo y que surgen tanto en el Derecho interno como en el Derecho Internacional.

7 Orlando Tovar Tamayo. "El marco jurídico del amparo en el derecho constitucional comparado». Revista de la Facultad de Ciencias Juridicas y Políticas. Caracas 1988. Págs. 130 y ss.

\& A pesar de que la Corte Suprema, en Sala Político Administrativa, sentencia 6 de marzo de 1986 limitara el amparo a los derechos enumerados explícitamente.

9 SCSJ. Sala Político Administrativa. 6 de agosto de 1987.

10 Ayala Corao "La ley órgania de amparo sobre derechos y garantías constitucionales». Caracas 1988. Pág. 145. 
No hay pues limitación en los derechos que se protegen con la tuición del amparo, ni puede circuscribirse la tutela y salvaguardia del más alto nivel a los derechos políticos, sociales o individuales, pues en dicha protección deben comprenderse todos, en la ya inmensa gama universal a la cual ha llegado el progreso humano, la cultura, los tratados internacionales y la evolución de la humanidad".

"Recordar el artículo 50 de la Constitución, como afirma Gustavo Briceño ${ }^{12}$, es avanzar significativamente desde el punto de vista social y jurídico, pues es evidente, que la dinámica que presenta el mundo actual, sería irrisorio y limitativo que los jueces ampararan a los ciudadanos sólo en aquellos derechos escritos en los textos normativos", ya que esto es cierto, el amparo en Venezuela se extiende a todos aquellos derechos que, sin estar regulados en cualquier precepto constitucional, son innatos al hombre ${ }^{13}$.

\section{PROCEDENCIA DEL AMPARO}

Para la procedencia del amparo se requiere habitualmente que exista un acto lesivo contra el cual reclamar la violación del derecho, y en este punto se hace necesario determinar cual es la naturaleza de dicho acto sobre el que se pretende interponer la acción de amparo.

Ignacio Burgoa ${ }^{14}$ define el acto lesivo como «cualquier hecho voluntario, consciente, negativo o positivo, desarrollado por un órgano del Estado consistente en una decisión o en una ejecución, o en ambas actuaciones conjuntamente, que produzcan una afectación en situaciones jurídicas o fácticas dadas, y que se impongan coactivamente", no obstante, el término acto lesivo debe interpretarse, en la legislación venezolana, en el sentido más amplio posible, involucrando todo hecho, positivo o negativo, y alcanzando, tanto a los actos emanados de autoridad pública, como de particulares.

"David Morales Bello. "Presentación del Proyecto de Ley de amparo". Diario de Debates de la Cámara de Diputados № 69. Pág. 1232.

23.

12 Gustavo Briceño. "Comentarios a la Ley de Amparo». Caracas 1988. Pág.

13 Esta enorme amplitud que se deduce del amparo venezolano dista, en mucho, de la protección otorgada por los instrumentos de similar naturaleza instaurados por otros ordenamientos latinoamericanos y por el ordenamiento español.

14 IgNACIO BurgoA. «El juicio de amparo». México 1975. Págs. 30 y ss. 
La Ley Orgánica de Amparo de 22 de Enero de 1988 ha reconocido expresamente que:

"La acción de amparo procede contra cualquier hecho, acto y omisión proveniente de los órganos del Poder Público... También procede contra el hecho, acto y omisión originados por ciudadanos, personas jurídicas, grupos u organizaciones privadas... (artículo 2)").

En los artículos siguientes reconoció la procedencia del amparo contra normas que violen o amenacen de violación la Constitución, sentencias o resoluciones de los tribunales que actúen fuera de su competencia, así como contra actos administrativos, actuaciones materiales, vías de hecho, abstenciones y omisiones que violen o amenacen de violación un derecho o una garantía.

\section{El Amparo contra leyes}

Quizás de las instituciones más novedosas que trae la Ley Orgánica de Amparo, sea el llamado "amparo contra leyes", que, sin duda, viene a completar y perfeccionar el sistema venezolano de control de constitucionalidad de las leyes. y la novedad va a radicar, precisamente, en el sentido de instaurar este instrumento en uno de los paises latinoamericanos que más importancia ha otorgado a la protección de la Constitución frente a ataques e injerencias provenientes de cualquier autoridad.

La norma contenida en el artículo 3 de la Ley de Amparo venezolana, es una traslación de la Ley Peruana ${ }^{15}$, pero debemos de admitir que en Perú no hay un control de la constitucionalida de las leyes tan completo como en Venezuela, donde el control de constitucionalidad ha evolucionado paralelamente al establecimiento del sistema Federal, hecho que, a su vez, ha marcado decisivamente su desenvolvimiento ${ }^{16}$.

En la legislación venezolana, al sistema mixto de control de contitucionalidad, marcado por la acción popular de inconstitucionalidad, la objeción de inconstitucionalidad, y la excepción de inconstitucionalidad, la Ley de Amparo viene a agregar un cuarto sistema de control, que permite el control de la constitucionalidad por los jueces de amparo, cuando conozcan de una acción de amparo ejercida contra una ley o acto normativo que, en forma directa e inmediata, viole o amenace de violación

15 Ley de Habeas Corpus y Amparo № 23506 de 7 de diciembre de 1982.

t6 Humberto Briceño León. "La acción de insconstitucionalidad en Venezuela». Caracas 1989. Págs. 84 y ss. 
un derecho fundamental, y que, por consiguiente colida con la Constitución ${ }^{17}$.

No obstante, el reconocimiento de la acción de amparo contra actos normativos, no invade la esfera de la acción de inconstitucionalidad venezolana; sus ámbitos procedimentales y de admisibilidad son distintos, y se perfeccionan a la vez. La acción de inconstitucionalidad prevista en la Ley Orgánica de la Corte Suprema, tiene como finalidad controlar la actividad de los poderes públicos, en cuando productores de actos generales o particulares y hacerla compatible con los principios constitucionales, y produce como consecuencia inmediata la revisión de un acto concreto del Poder público, y no la revisión o control de una relación entre sujetos; supone la confrontación entre una norma formalizada por el constituyente y un acto formal proveniente del Poder público.

La acción de inconstitucionalidad tiene por objeto una reconstrucción objetiva; subsanar o reponer la situación de ataque al contenido de un dispositivo jurídico constitucional, en cambio, la esencia de la acción de amparo no es independiente o autónoma del acto jurídico objetivo que se pretende viola la Constitución.

El amparo es una garantía procesal para lograr la urgente vigencia de los derechos constitucionales y su desarrollo, "mediante la cual se ratifica la obligación del Estado de dar protección a los derechos que corresponde a los ciudadanos ${ }^{18}$.

El amparo es la obligación de dar vigencia real a los derechos, como también ha de hacerse con los instrumentos y recursos ordinarios que a tal efecto tienen dispuestos los ordenamientos jurídicos, no tratándose de una acción residual en el sentido de que opere por no existir el marco de la ley recursos o acciones ordinarios más o menos vinculados al logro de una declaración procesal relativa al hecho trasgresor de una disposición cosntitucional.

La disposición del artículo 49 de la Constitución instaura una garantía procesal que se concreta en los procesos judiciales para asegurar la vigencia real de los derechos, por lo que se justifica el amparo contra leyes que privan de la posibilidad de existencia de los derechos, bien sea por ineficaces, por constituir las vías procesales fórmulas negatorias de los derechos, por dificultosas, tardías o inútiles, con lo cual se persigue

17 Brewer Carias. "Estado de Derecho y Control Judicial». Opus cit. Págs. 19 y ss.

18 Humberto Briceño León. Opus cit. Pág. 67. 
lograr una situación jurídica que reponga la circustancia concreta de una normalidad para quien requiere amparo.

\section{El Amparo contra sentencias y resoluciones judiciales}

Sin duda alguna podemos determinar que la aceptación en Venezuela de la acción de amparo contra sentencias trae su origen en un aspecto peculiar de la institución mexicana, que durante largo tiempo se diferenció del resto de los paises latinoamericanos, cual es la posibilidad de impuganción de las resoluciones judiciales, cuando se establezca que en las mismas no se han amplicado, o se han aplicado incorrectamente las disposiciones legales, dando lugar a lo que en México se ha dado en llamar "amparo casación" ${ }^{19}$ debido a su similitud con el recurso de casación.

Como consecuencia de la afirmación inicial hecha por el legislador en el sentido de que la acción de amparo procede contra los actos provenientes del Poder público Nacional, la ley venezolana prevé la procedencia del amparo contra actos del Poder Judicial, cuando reconoce:

"lgualmente procede la acción de amparo cuanto un Tribunal de la República, actuando fuera de su competencia, dicte una resolución o sentencia u ordene un acto que lesione un derecho constitucional" (artículo 4).

Pese a que, en un primer momento, la jurisprudencia venezolana restringió la procedencia de la acción de amparo contra actos judiciales, tal vez por temor a posibles injerencias, ha sido la misma jurisprudencia la que, a través de su evolución, ha perfilado la aceptación de la misma.

«No otorga la Ley Orgánica la acción de amparo contra sentencias de forma indiscriminada (afirmaba en un momento la Corte Suprema de Justicia) ${ }^{20}$, porque el Poder Judicial, a parte de que es el garante del Estado de Derecho, es el único que ejerce el control de constitucionalidad y legalidad de los actos emanados de las otras ramas del Poder Público y de cualquiera otros órganos, organismos y entes públicos... Debido a ello, admite la acción de amparo contra decisiones judiciales pero limitada a los casos de actuaciones efectuadas fuera de su competencian. Pero, al efectuar una exégesis de la norma comprendida en la Ley de Am-

19 FIX ZAMudio. «Reflexiones sobre la naturaleza procesal del amparo». Revista de la Facultad de Derecho de México № 56.1964. Pág. 985.

20 SCSJ. Sala Casación Civil. 1 de junio de 1989. 
paro, los tribunales expresaron que ella no se refiere a los problemas de competencia en un sentido procesal estricto, pues éste es un asunto de hecho, $y$, al respecto, los Códigos establecen sus propios mecanismos para regularla, por lo que la interpretación se colocaba, más bien, cerca del aspecto constitucional de la función pública.

Para que obre un amparo contra decisiones judiciales es necesario que el caso que se trate pueda subsumirse dentro de los clásicos conceptos de "abuso de autoridad" y "usurpación de funciones", es decir, cuando un Tribunal ha dictado un pronunciamiento con manifiesta usurpación de funciones o ejerciendo una no conferida por la ley, y con su conducta vulnere o afecte una garantía constitucional.

Del contendio literal de la norma del artículo 4 de la Ley de Amparo puede entenderse la concurrencia de dos presupuestos de hecho para que prospere el conocimiento de la acción de amparo contra una decisión judicial: la incompetencia del Tribunal, y la lesión de un derecho fundamental, y debido a la necesidad de flexibilizar posturas, ya que la postura inicial puede conducir al absurdo de una manifiesta violación de un derecho constitucional efectuado por un juez que actúa dentro de la esfera de sus competencias y tal actuación se ainmune al recurso de amparo, "se entiende que la existencia de uno solo de los requisitos es suficiente para revisar el acto cuestionado" ${ }^{21}$.

La única excepción que se establece a las acciones de amparo contra decisiones judiciales, es la imposibilidad de ejercerla contra las resoluciones de la Corte Suprema de Justicia, hecho que tiene su apoyatura en el artículo 211 de la Constitución venezolana, así como en la Ley que regula la Corte Suprema ${ }^{22}$, que configuran a la Corte como el más alto Tribunal de la República y la máxima representación del Poder Judicial, por lo que no existe órgano judicial por encima de él, además de establecer dichas normas que contra las decisiones que dicte, en Pleno o en alguna de sus Salas no se oirá ni se admitirá recurso alguno".

\section{El Amparo frente a actos provenientes del Estado}

El Poder se manifiesta de diferentes formas, para lo cual el ordenamiento jurídico confiere modalidades de actuación de los distintos poderes, siendo el Poder Ejecutivo, dada la variedad de fines del Estado,

21 SCSJ. Sala Casación Civil. 8 de noviembre de 1989.

22 Artículo 1 de la Ley Orgánica de la Corte Suprema de Justicia de 30 de julio de 1976. 
quien tiene una forma incontable e ilimitada de actuación. Ahora bien, la procedencia del amparo frente a actos del Estado, lo es respecto a actos de efectos particulares, ya que tal vía está constituída por una acción, un remedio que se busca para una lesión personal, aun cuando los accionantes o recurrnetes sean varias personas. No puede hacerse valer frente a un acto general, por cuanto de ser acordado, rompería la igualda de los ciudadanos ante la ley ${ }^{23}$, y quienes obtuvieran el amparo quedarín liberados del vínculo de la misma, a diferencia de los restantes miembros de la comunidad que continuarian sometidos a ella, lo cual contituiría una situación inadmisible por ser violtorio del principio de igualdad.

Uno de los rasgos característicos del proceso de amparo, es que éste tiene carácter personal e individualizado, por lo que ningún accionante puede arrogarse la representación de todos los habitantes del país, y mucho menos puede el Tribunal acoger tal representación y extender la protección acordada a todos, puesto que la acción de amparo no tiene efectos "erga omnes", sino efectos relativos interpartes, el amandamiento de amparo solo puede cubrir específicamente a los sujetos que intervienen en este proceso ${ }^{24}$.

Aunque en un principio la acción de amparo no fue admitida por los Tribunales venezolanos frente a actos administrativos, ésta tiene especial relevancia como medio de protección de derechos constitucionales causadas por actos estatales no normativos, $y$, particularmente, por actos administrativos de efectos particulares, $y$ este ha sido el sentido que de la misma jurisprudencia le ha otorgado. Por el fin que persigue la Constitución en su artículo 49 de inmediata protección de las garantías constitucionales, cuando los medios ordinarios que existen contra actos administrativos inconstitucionales o ilegales, sean insuficiente, o no idóneos, la acción de amparo resulta procedente, "y si esta idoneidad o insuficiencia se agrega a la incertidumbre en que se coloca al interesado respecto al ejercicio de un derecho por la no operatividad inmediata del recurso ordinario o normal contra el acto ilega, está plenamente justificado el amparo como pretensión procesal autónoma» ${ }^{25}$.

En muchas ocasiones hablar de acto lesivo o reclamado puede dar la impresión de que se quiere designar un hecho positivo que se comete mediante una determinada actividas, sin embargo en el concepto acto lesivo hay que involucrar también los hechos negativos, es decir, las abs-

23 Hildegard Rondón de Sansó. «El Amparo Constitucional». Caracas 1988. Pág.

75.

24 SCSJ. Sala Político Administrativa. 6 de agosto de 1987.

$25 \quad$ SCPCA de 20 de enero de 1986. 
tenciones $u$ omisiones que provocan perjuicio en detrimento de un derecho o una libertad. No siempre la contravención emana de un acto positivo, también puede ser causado el daño por inacción, retardo o suspendiendo $\mathrm{y}$ omitiendo la realización de un acto, $\mathrm{y}$ estas consideraciones parten, cuando se refieren al Estado, de la idea central de la titularidad estatal de ciertos deberes, cuyo cumplimiento es necesario para la consecución del bien común, fin justificativo del Estado como tal.

El acto lesivo puede implicar una acción, omisión o retardo ${ }^{26}$, y en el orden público, la omisión o retardo del ente agraviante tiene por comienzo la violación del derecho constitucional de petición, consagrado en el artículo 67 de la Constitución venezolana, que reconoce a todos uel derecho de representar o dirigir peticiones ante cualquier autoridad pública sobre asuntos que sean competencia de éstos y a obtener oportuna respuesta", para que, de esta forma, mediante el amparo se restablezca inmediatamente la situación jurídica en la que se coloca al peticionario, causándole indefensión y afectándolo con la incertidumbre que resulta de la falta de oportuna respuesta o cumplimiento ante una solicitud coincreta de proceder o actuar frente a la obligación legal expresa que impongan a la Administración un deber preciso de hacer, no hacer o dar ${ }^{27}$.

\section{El Amparo por violación del derecho a la libertad: el Habeas Corpus}

El Amparo protege la universalidad de los derechos individuales inscritos en la Constitución, pero en lo que respecta a la efectiva garantía de la libertad personal y física del hombre, existe una vía especial, tradicionalmente conocida bajo el nombre de "Habeas Corpus" ${ }^{28}$. El amparo es el género y el Habeas Corpus la especie ${ }^{29}$, y se diferencian en su contenido y extensión, pues mientras el amparo envuelve un concepto global de los derechos inherentes a la persona, el habeas corpus se concreta en la privación o restricción de la libertad.

No obstante también existen diferencias en lo que respecta al régimen funcional y estructura procesal. El Habeas Corpus tiene fisonomía pro-

26 SCSJ. Sala Político Administrativa de 6 de agosto de 1987.

27 RoMero MuCl. «El amparo constitucional por omisión o retardo». Biblioteca de la Academia de Ciencias Políticas y Sociales. Caracas 1989. Págs. 58 y ss.

28 Otto Marín Gómez. "La protección procesal de las garantías constitucionales: amparo y Habeas Corpus». Caracas 1983. Pág. 9.

29 Hernando Crisanti Aveledo. "El amparo de la libertad personal» IEJE Lara. Barquisimeto. Págs. 181 y ss. 
pia, tiende a proteger al individuo contra los actos arbitrarios que afectan a su libertad, mientras que el amparo tiende a asegurar el disfrute de los demás derechos. El uso del Habeas Corpus se ha reservado generalmente para precaver la libertad física y por ello en el acontecer histórico surge como la primera garantía alcanzada por el hombre ya que su restricción o suspensión entraña y limita el ejercicio de los demás derechos individuales ${ }^{30}$.

El amparo de la libertad y seguridad personal, derecho garantizado en la Constitución venezolana ${ }^{31}$, y reglamentado antes que la acción de amparo, fue regulado por la Ley Orgánica de Amparo, la cual dedicó su Título $\mathrm{V}$ a definir los principios fundamentales que regirían la detención y las garantías del detenido, sin perjuicio de que le sean aplicables las disposiciones que la Ley dedica al amparo en general, con lo cual dejó de tener vigencia la Disposición Transitoria $5^{\mathrm{a}}$, consiguiéndose un mayor grado de desarrollo de la Constitución de 1961.

La Ley Orgánica de Amparo, además de establecer normas procesales relativas al amparo de la libertad y seguridad personal, establece una serie de principios relativos a la privación de libertad por parte de las autoridades públicas, prescribiendo límites temporales precisos para ello. Así, el artículo 44 preceptúa que las detenciones que se ordenen y practiquen por las autoridades policiales o administrativas no excederá de 8 días, estableciéndose que aquellas que superen las 48 horas deberán imponerse mediane resolución motivada, y reconociéndose que cuando se hubiera cometido un hecho punible, la policía judicial podrá adoptar como "medidas provisionles de necesidad y de urgencia" la detención del presunto culpable o su presentación periódica, durante la averiguación sumarial, a la autoridad competente, debiendo ser la orden motivada, en garantía del detenido, y éste deberá ser pueto en el término de 8 días ante el juez competente, competencia que se atribuye a los Jueces de $1^{\mathrm{a}}$ Instancia de lo Penal, otorgándose a los respectivos Tribunales superiores la facultad de conocer en consulta las sentencias dictadas por aquellos (artículo 40), para lo que deberán enviarse los recaudos en el mismo día o el siguiente, sin que la consulta impida la ejecución inmediata de la decisión.

\section{Improcedencia de la acción de Amparo}

El ejercicio de la acción de amparo, de acuerdo con lo establecido en la Ley, procede cuando haya "violación o amenaza de violación", de un

30 Álvarez M. Victor. "Recuso de amparo y Habeas Corpus en Venezuela». Academia Ciencias Políticas y Sociale. № 2. Caracas 1982. Pág. 84.

31 Disposición transitoria $5^{\mathrm{a}}$ de la Constitución de 1961. 
derecho o garantía, aun cuando éstas no estén consagradas en el texto constiotucional, siempre que aquellas sean actuales, reparables y no consentidas, y además, como criterios determinantes para la procedencia de la acción de amparo, frente a las vias ordinarias ${ }^{32}$, se determina que estas vías no sean idóneas para evitar el daño o la lesión causada a los derechos, no sean suficientes para reparar el perjuicio o daño causado, no sean oportunas para lograr el restablecimiento inminente de las situaciones juridicas infringidas, criterios que actúan como condiciones alternativas, ya que cualquiera de ellos es suficiente para justificar la procedencia de la acción, como medio especial de protección de los derechos.

La falta de concurrencia de los presupuestos a los que se ha aludido va a determinar que la demanda, en lugar de producir el examen de la pretensión que contiene, y la posterior decisión judicial, sea rechazada, no entrnado el juez a conocer del asunto.

La acción de amparo, de acuerdo con lo establecido en al artículo 6 de la Ley Orgánica, será improcedente en los siguientes caso;

a) Cuando haya cesado la violación o amenaza de algún derecho o garantía que hubiesen podido causarla.

b) Cuando la amenaza contra el derecho o garantía constitucional no sea inmediata, posible y realizable por el imputado.

c) Cuando la violación del derecho o la garantía constituyan una evidente situación irreparable, no siendo posible el restablecimiento de la situación jurídica.

d) Cuando la acción u omisión haya sido consentida.

e) Cuando el agraviado haya optado por recurrir a las vías judiciales ordinarias o hecho uso de los medios jurisdiccionales preexistentes.

f) Cuando se trate de decisiones emanadas de la Corte Suprema de Justicia.

g) En los casos de suspensión de derechos y garantías constitucionales.

h) Cuando esté pendiente de decisión una acción de amparo ejercida ante un Tribunal en relación con los mismos hechos que hubiesen fundamentado la acción prepuesta.

32 SCSJ. Sala Político Administrativa de 6 de agosto de 1987. 


\section{LA LEGITIMACIÓN EN EL PROCESO DE AMPARO}

El amparo constitucional, de conformidad con el precepto rector, se distingue por su universalidad. Como tuición del más alto nivel, protege y ampara a todos, sin excepciones ni discriminaciones, y ese carácter general que el constituyente signó, es el carácter que otorga una nota de amplitud ética para acabar a todos los habitantes, cualquiera que sea su condición ${ }^{33}$.

Están legitimados activamente en el proceso de amparo las personas naturales, ya sean nacionales o extranjeras, como consecuencia del artífculo 45 de la Constitución que otorga a los extranjeros los mismos derechos y deberes que poseen los venezolanos, con las limitaciones y excepciones establecidas por el texto constitucional y las leyes, así como las personas juridicas que estén domiciliadas en la República.

Con relación a las personas jurídicas políticas, territoriales o no, Estados, Nación, Municipios y entes de la administración descentralizada, cuando actuán exclusivamente como personas de Derecho Público, hay que entender que están excluídas de ejercer tal acción, ya que estos entes administrativos están capacitados como sujeto de derecho para tutelar por sí mismos sus propias situaciones jurídicas, eximiéndose de este modo de la necesidad de recabar tutela judicial ${ }^{34}$, si por el contrario se trata de personas de Derecho Privado, se aplicarán las normas generales de legitimación activa.

La acción de amparo constitucional puede ser interpuesta ante el juez competente por cualquier persona, directamente o por representación, siempre que ésta quede suficientemente acreditada y, dada la naturaleza constitucional de la acción de amparo, el legislador ha querido dotarla de la mayor flexibilidad posible para que resulte práctica y eficaz, por lo que ha permitido que el agraviado pueda actuar directamente, sin necesidad de asistencia letrada.

La acción de amparo se interpone mediante una solicitud verbal o escrita, incluso por vía telegráfica (artículo 16 y 41 ) y además su tramitación es breve, simple y sumaria, teniendo el juez competencias inquisitivas especiales como director del proceso, y en su tramitación interviene

33 David Morales Bello. "Presentación del Proyecto de Ley de amparo". Opus cit. Pág. 1232.

34 García de Enterría y Ramón Fernández. "Curso de Derecho Administrativo I". Madrid 1982, Pág. 245. 
el Ministerio Público, o los Ministerios especiales, como parte de buena fé.

El interés procesal denota la relación de identidad entre el efectivo titular de la acción y la persona que concretamente la ejercita, es decir, entre la persona del actor, legitimado activo, y de la persona a quien la ley concede la acción, y de la persona del demandado con la persona contra quien la acción es concedida.

En el caso de la acción de amparo, el interés debe ser personal y directo, requiere una lesión personal y directa en los derechos constitucionales del legitimado activo. Ese interés para ejercer la acción de amparo resulta similar al requerido para intentar los recursos de nulidd contra los actos de efectos particulares que requieren un interés personal y directo en impugnar el acto de que se trate ${ }^{35}$.

La legitimación pasiva en el proceso de amparo constitucional venezolano está constituida por aquel de quien provenga la lesión al libre ejercicio y goce de los derechos constitucionales. Los constituyentes primero, y los legisladores después, pretendieron dar tal amplitud al amparo, que aceptaron éste no sólo respecto a los actos, hechos $u$ omisiones de los Poderes Públicos, sino también admitieron el amparo para tutelar las vuleneraciones ocasionadas por acciones y omisiones de los particulares.

El sistema venezolano, como hemos vito, establece la posibilidad de accionar de amparo cuando alguno de sus órganos investidos de publicidad, $y$ en tanto que sometidos al Derecho Administrativo, o Privado, pero actuando como órganos público, lesione o pueda lesionar el ejercicio de los derechos, incluso los funcionarios o autoridades públicas que ejercen el Poder, cuando lesionen o amenacen de lesión derechos y garantias, adquieren especial relevancia como legitimados pasivos en los procesos de amparo, ahora bien, es importante señalar que el amparo venezolano no sólo protege frente a las arbitrariedades procedentes del Estado, también procede contra el hecho, acto y omisión originados por ciudadanos, personas jurídicas, grupos, organizaciones privadas que hayan violado, violen o amenacen violar cualquiera de las garantías o derechos amparados por la ley, lo que determina el carácter práctico, flexible $y$ operativo del amparo como institución que pretende defender el ejercicio y respeto de los derechos.

Evidentemente, el ordenamiento jurídico venezolano ha arbitrado diversos mecanismos y acciones tato civiles como penales, mediante las

35 Ayala Corao. Opus cit. Pág. 139. 
cuales se puede hacer efectivo el respeto a las normas constitucionales, pero ninguna de ellas reúne los requisitos de sumariedad y preferencia que impone el artículo 49 de la Constitución pra la defensa de los derechos y garantías, lo que determinó que los legisladore, movidos por e imperativo constitucional, y por la influencia sufrida del ordenamiento argentino, hicieran extensivo el amparo a los actos contra particulares.

\section{LA COMPETENCIA PARA CONOCER LA ACCIÓN DE AMPARO}

El conocimiento de la solicitud de amparo debe hacerse en absoluto sometimeinto a las normas establecidas en la ley, la competencia debe corresponder al juez competente, a quien le haya sido atribuida la competencia por virtud de la ley, y esa competencia, con el apoyo de la jurisprudencia elaborada por los tribunales y, en especial por la Corte Suprema, debe ser múltiple y guardar afinidad con el derecho conculcado ${ }^{36}$.

El principio general de competencia en materia de amparo de los derechos y garantias, distintos del derecho a la libertad y seguridad personal, es que los tribunales competentes son los Tribunales de 1a Instancia, según la afinidad de su competencia con el derecho violado (materia), en la jurisdicción del lugar donde el acto, hecho y omisión ocurra (territorial).

Sin embargo este principio general de competencia tiene dos excepciones generales en la ley: la primera como garantía de acceso a la justicia constitucional viene regulada en el artículo 9, donde se reconoce que cuando los hechos y omisiones constitutivos de violación se produzcan en lugar donde no funcionen tribunales de $1^{a}$ Instancia, se interpondrá la acción de amparo ante cualquier juez de la localidad quien decidirá conforme a lo establecido en la ley, debiendo éste enviar en consulta la decisión al Tribunal competente en el plazo de veinticuatro horas.

La segunda excepción al principio general se refiere a los casos en lo cuales la violación o amenaza sea producida por actos y omisiones de ciertos órganos constitucionales. A la entrada en vigor de la Ley de Amparo, el artículo 8 otorgaba competencia a la Corte Suprema de Justicia

${ }^{36}$ Diario de Debates de la Cámara de Diputados del Congreso de la República. Octubre-noviembre. Pág. 1233. 
para conocer, en única instancia, de la acción de amparo contra actuaciones y omisiones emanados del Presidente de la República, de los Ministros, del Fiscal General de la República, del Procurador General de la República o del Controlador General de la misma, y, en virtud de la excepcionalidad que implica la competencia "rationae persona", la enunciación de autoridades debía considerarse en sentido estricto y limitativo ${ }^{37}$, no obstante el contendio de este precepto sería objeto de modificación posterior en virtud de la Ley de Reforma Parcial de la Ley Orgánica de Amparo de 27 de Septiembre de 1988, ante la observación de los acontecimientos surgidos con motivo de acciones de amparo ejercidas por particulares ante tribunales de la jurisdicción ordinaria en relación con decisiones adoptadas por el Consejo Supremo electoral. La reforma se concretó en el artículo 8 de la Ley de Amparo y se precisó mediante el añadido a la mecnicón "del Consejo Electoral Supremo y demás organismos electorales del país» entre los altos funcionarios del Estado y organismos estatales enunciados en dicho artículo, para someterse a la jurisdicción del más alto tribunal de la República el conocimiento de las acciones de amparo contra actos u omisiones emanados de ellos.

Junto a los principios generales y sus excepciones en materia de competencia para conocer la acción de amparo, la Ley trae otra serie de principios especiales de competencia, estableciéndose en virtud de la persona de la cual emana la lesión, o en razón de la organización de la competencia judicial por el grado. Así, en principio, los Tribunales de $1^{\text {a }}$ Instancia del lugar de agravio, en razón de la materia del derecho Constitucional lesionado, son competentes para conocer de la acción de amparo contra leyes y demás actos normativos, teniendo la norma especial interés en el caso de los actos normativos, teniendo la norma especial interés en el caso de los actos dictados por las Asambleas Legislativas de los Estados y los Concejos Municipales (artículo 5), a cuyo efecto, la ley solo dispone que el juez informará de su decisión a la Corte Suprema. Sin embargo, cuando la acción de amparo se interpone conjuntamente con la acción populr de inconstitucionalidad de leyes o demás actos estatales normativos, será competente la Corte Suprema en razón de la competencia legal asignada para conocer de la acción de nulidad, según establece el artículo 3 de la Ley de Amparo y el artículo 42, ordinales 1, 2 y 3 de la Ley Orgánica de la Corte Suprema.

Por razones de evidente orden jerárquico en la organización judicial, en los casos de acciones de amparo contra actos judiciales, será competente el Tribunal Superior al que emitió el pronunciamiento, pero entendiéndose que la superioridad viene dada de forma escalonada, y

37 Ayala Corao. Opus cit. Pág. 50. 
que, en este supuesto, no debe intentarse directamente ante la Corte Suprema ${ }^{38}$.

\section{CARACTERÍSTICA DEL PROCESO DE AMPARO CONSTITUCIONAL}

Cuando la Constitución de 1961 reconocia en su artículo 49 el amparo de los derechos y garantías, estableció que el procedimiento debería ser breve y sumario, otorgando al juez competente la potestad para el restablecimiento inmediato de la situación violada, sin embargo, la ausencia de una ley reguladora de este artículo no impidió que se iniciasen una serie de procesos de amparo, hecho que llevó a los jueces a adoptar y utilizar, por analogia, los procedimientos sumarios que existian en el derecho positivo venezolano, bajo el fundamento de una resolución de la Corte Suprema ${ }^{39}$, según la cual, "era obligación de los tribunales suplir por medio de la analogía y demás instrumentos de interpretación de que los prové el sistema jurídico, la lamentable ausencia de una ley reguladora de la materia".

Posteriormente la jurisprudencia del Máximo Tribunal delineó como principios propios de la tramitación del amparo, la exigencia de que el procedimiento, además de cumplir a satisfacción con el requisito constitucional de brevedad y sumariedad, garantizara la intervención de la parte contraria como garantía del derecho a la defensa del mismo rango constitucional ${ }^{40}$, lo que hcía que el legislador tuviera que configurar un modo de actuación para los actos de los interesados estructurado a base de escasas actuaciones y a plazos abreviados para tratar de llegar a una sentencia rápida.

La Ley Orgánica, siguiendo las orientaciones de la jurisprudencia ha regulado un procedimiento basado en los siguientes principios:

\section{Brevedad:}

El procedimiento breve es aquel en el cual, por razones de urgencia, o por tener un carácter sumario, se hace preciso prescindir de toda

38 SCSJ. Sala Casación Civil de 27 de abril de 1988.

${ }^{39}$ SCSJ. Sala Político Administrativa de 20 de octubre de 1983.

40 SCSJ. Sala Político Administrativa de 12 de agosto de 1986. 
dilación que no sea absolutamente inevitable y de cuantas formalidade embaracen su curso rápido ${ }^{41}$.

Esta característica de brevedad se siente en el espíritu y en el articulado de la Ley, la cual establece una serie de principios tendentes ahacerla efectiva. En efecto, en cuando a la dedicación del tribunal para conocer de la acción de amparo, el artículo 13 señala que todo tiempo será hábil, lo que impide que se apliguen la supresión de lapsos procesales y los límites de horas para despachar previstos en el Código de Procedimiento Civil, además se establece el carácter preferencial del amparo "sobre cualquier otro asunto", disponiendo incluso, respecto a la acutación del Ministero Fiscal, cuya función es velar por el respeto de los derechos y garantías, que ésta no podrá afectar a la agilidad del procedimiento de amparo, ya que los jueces que conozcan de la acción de amparo no podrán demorar el trámite o diferirlo so pretexto de consultas al Ministerio Fiscal (artículo 15), puesto que la solución inmediata para el restablecimiento del derecho infringido es más importante que su opinión, máxime si el representante fiscal se encuentra a derecho, una vez que el juez competente lo hubiera participado.

Con el fin de dar cumplimiento al mandato de brevedad, la ley ha prescrito unos lapsos procesales precisos y breves, de estricto cumplimiento, calificando la Ley (articulo 34) como falta grave el incumplimiento de los mismos, norma que viene a agregar una sanción adiciona, de suspensión del cargo, prevista en el artículo 43 de la Ley de la Carrera Judicial.

\section{Sumariedad y celeridad:}

Conviniendo que lo específico de un procedimiento sumario es la reducción y simplificación de los actos y trámites judiciales, aunque no la elimionación de la actividad de las partes en el proceso ${ }^{42}$, para facilitar la sumariedad y celeridad, el artículo 16 permite que la acción de amparo, en caso de urgencia, pueda ser interpuesta por vía telegráfica o que el ejercicio de la acción pueda ejercitarse de forma verbal.

Es esencial al procedimiento de amparo la celeridad, y ello deriva del fin mismo que pretende la figura, el restablecimiento inmediato en el goce y ejercicio de un derecho, por lo que se exige que el procedimiento deba estar informado por una serie de principios ${ }^{43}$ :

41 Gustavo Linares Benzo. «El proceso de amparo en Venezuela». Caracas 1987. Pág. 75. Cita a Argimiro Borjas.

42 SCSJ. Sala Político Administrativa de 14 de agosto de 1990.

43 Gustavo Linares Benzo. Opus cit. Pág. 78. 
- Debe ser simple, sin reglas rituales que entorpezcan el logro de su finalidad.

- No debe sufrir detención, si las partes no lo impulsan debe hacerlo el juez.

- Debe respetar el principio de inmediación en virtud del cual el juez debe mantener contacto inmedito con las prtes y vigilar personalmente la prueba.

- No puede exigirse durante el transcurso de juicio incidentes que lo retrasen.

Con respecto a este último punto, la sumariedad implica la exclusión de todo trámite incidental, por lo que la promoción de cuestiones previas, o la oposición de alguna de las causales de improcedencia, deben ser resueltas en la decisión definitiva del proceso de amparo ${ }^{44}$.

\section{Orden Público:}

El orden público es una expresión que tiende a señalar que el Estado aparece como parte interesada en el proceso y tiene un interés fundamental en la solución jurídica de la controversia ${ }^{45}$, señalando la Ley que la acción de amparo, tanto en lo principal como en la incidental, y en todo lo que de ella derive, hast ala ejecución de la resolución es de orden público, por ello, de acuerdo con el artículo 25, quedan excluídas del procedimiento constitucional de amparo todas las formas de arreglo entre las partes, aunque esta mismo norma añade que el arreglo se podrá efectuar "cuando no se trate de un derecho de eminente orden público o que pueda afectar a las buenas costumbres", por lo que deducimos que no existe ninguna forma de arreglo entre las partes, no obstante la idea de exclusión de arreglo no impide que el autor del agravio pueda convenir el restablecimiento inmedito de la situación infringida, porque de lo contrario iría ucontra la lógica juridico-procesal, el sentido y la finalidad de la acción misma» ${ }^{46}$.

\section{Carácter inquisitivo:}

El procedimiento de amparo otorga al juez amplios poderes para conducir el procedimiento, e incluso evacuar pruebas de oficio (artículo

44 Brewer Carías. "La Ley de amparo». Opus cit. Pág. 86.

45 Gustavo Briceño. Opus cit. Pág. 55.

46 Ayala Corao Opus cit. Pág. 189. 
17) a los efectos de garantizar la protección constitucional, siempre que no supongan perjuicio irreparable cuando exista otro medio de prueba más acorde con la brevedad del procedimiento, o cuando la prueba se ade difícil o imposible reparación.

\section{PROCESO ORDINARIO DE AMPARO}

Iniciación del procedimiento:

- A instancia de parte interesada mediante solicitud escrita, telegráfica o verbal (artículo 16).

- Solicitud (artículo 18):

- Identificación del agraviado.

- Identificación del agraviante.

- Señalamiento del derecho o garantía violada.

- Descripción del hecho, acto y omisión.

- Otros extremos.

Tramitación del procedimiento:

- Admisión de la solicitud:

- Revisión de los aspectos formales de la solicitud.

- Exámen de los requisitos de admisibilidad.

- Comunicación al Ministerio Fiscal.

- Posibilidad de declarar mandamiento de amparo provisional (artículo 22).

- Notificaciones a las partes e interesados.

- Informes en el plazo de 48 horas.

- Audiencia pública constitucional en el plaza de 96 horas.

Terminación:

- Desistimiento.

- Sentencia en el plazo de 24 horas:

- Autroidad, ente privado o persona contra cuya actuación se concede el amparo.

- Orden a cuplir.

- Plazo para cumplir lo resuelto.

- Ejecución de la sentencia. 